\title{
Increased Incidence of Adult Complicated Appendicitis in One Resource-Competent Community during the Coronavirus Disease 2019 Pandemic: Time to Improve Health-Seeking Behaviors
}

Jin-Ming Wu ( $\square$ wujm0531@ntu.edu.tw)

National Taiwan University Hospital https://orcid.org/0000-0002-1821-239X

Te-Wei Ho

National Taiwan University Hospital

Hsi-Yu Yu

National Taiwan University Hospital

I-Rue Lai

National Taiwan University Hospital

Research article

Keywords: Health-seeking behavior, COVID-19, appendicitis, surgical care

Posted Date: August 23rd, 2021

DOl: https://doi.org/10.21203/rs.3.rs-806063/v1

License: (9) This work is licensed under a Creative Commons Attribution 4.0 International License. Read Full License 


\section{Abstract}

\section{Background}

The impact of the coronavirus disease 2019 (COVID-19) pandemic on medical services is overwhelming due to limited medical resources. During its initial surge in 2020, Taiwan's government rapidly established diverse public actions, which helped maintain the medical supply without travel restrictions. However, whether the fear of being infected with COVID-19 interfered with health-seeking behavior (HSB) remains unclear. Therefore, this study aimed to elucidate whether acute complicated appendicitis (ACA) rates in adults were affected by the COVID-19 pandemic.

\section{Methods}

A retrospective analysis of acute appendicitis in adults was performed between January 1 and June 30, 2020 (COVID-19 period). The control period was collected from the first two quarters for the preceding 3 years. Outcome measures were ACA and length of hospital stays.

\section{Results}

A total of 145 patients with acute appendicitis presented to our institution during the COVID-19 era. Compared to a 3-year control cohort of 320 patients, the COVID-19 pandemic was associated with a higher rate of symptom duration until their presentation to the emergency room within $>48 \mathrm{~h}(17.2 \% \mathrm{vs}$ $9.1 \%, P=0.011)$, a higher incidence of ACA $(29.7 \%$ vs $19.4 \%, P=0.014)$, and a longer length of hospital stays ( 5.0 days vs 4.0 days, $P=0.043$ ) were observed. In the adjusted regression analysis, the COVID-19 period was significantly associated with a higher rate of ACA (odds ratio [OR] $=1.87 ; 95 \%$ confidence interval [Cl]: $1.23-2.52 ; P=0.008)$ and longer length of hospital stay $(\mathrm{OR}=2.10 ; 95 \% \mathrm{Cl}: 0.92$ to $3.31 ; P<$ $0.001)$.

\section{Conclusions}

The COVID-19 pandemic was significantly associated with increased ACA rates in one community with a normal medical supply. The fear of being infected with COVID-19 may prohibit patients from seeking medical needs. To improve HSB during the pandemic, a surgical community should attempt to provide scientific information to the public and maintain surgical services under the coverage of workplace safety.

\section{Introduction}

Health-seeking behavior (HSB) is described as "steps taken by a patient who perceives a need for help when he or she tries to solve a medical disease."[1] In other words, HSB is the behavioral element of healthcare utilization and is conceptually associated with clinicodemographic, socioeconomic status, access to healthcare institutes, and views and experiences of both patient and medical provider.[2,3] Andersen has developed a serial behavioral model to elucidate mechanisms associated with healthcare 
utilization, $[2,4]$ defined as the quantity of using healthcare services and estimated by costs and medical visits.[5]

The new variant of severe acute respiratory syndrome coronavirus disease 2 (SARS-CoV-2), also known as coronavirus disease 2019 (COVID-19), first broke out in China in December 2019 and rapidly spread worldwide.[6] As of September 30, 2020, 33.83 million confirmed cases and > 1.01 million deaths were cumulatively recorded worldwide since the start of the pandemic according to the World Health Organization statistics.[7] The high contagious potential of COVID-19 deepened the strain on healthcare institutes and resulted in reduced healthcare utilization worldwide under a limited supply of medical resources. Further, the patient with severe illnesses might be unwilling to visit the highly contagious hospital due to the fear of being infected by the virus.[8]

Acute appendicitis (AA) is not only one of the most common causes of acute abdominal diseases in adults[9] but also one of the most common reasons for general emergency surgery worldwide.[10] With the advancement of minimally invasive surgery, most patients can recover early by timely appendectomy. [11] However, the COVID-19 pandemic becomes a barrier to timely surgical treatment, which increases the acute complicated appendicitis (ACA) rate in countries with compromised medical supplies.[12, 13]

Taiwan is very close to the coast of China and was anticipated as one with the highest number of cases in 2020 due to many flights between each country. However, Taiwan surprisingly controlled the sporadic outbreak of COVID-19 well by implementing several public health responses[14] and was free from the shortage of medical resources. As a result, it provides a unique environment (patients were in mental panic due to COVID-19) to validate if HSB may interfere with clinical outcomes even in a resourceunlimited setting. In this study, we hypothesized that mental panic deteriorated the outcomes. Thus, we aimed to analyze the rates of uncomplicated/complicated appendicitis during the COVID-19 pandemic and compared them with that of previous years.

\section{Methods}

A retrospective study was conducted to review records of adult patients with $\mathrm{AA}$ ( $\geqq 20$ years) in one academic center, during the COVID-19 epidemic period from January to June 2020. Next, patients with AA from the same months, January to June, in 2017, 2018, and 2019 were considered as the control group. The same interval every year was analyzed because a previous study demonstrated that the incidence of AA was associated with seasonal variation.[15] The exclusion criteria were pregnant women or pathological findings with appendiceal tumors. This study was reviewed and approved by the research ethics committee of the National Taiwan University Hospital (202008052RINC).

Data analyzed included clinical demographics, such as age, gender, body mass index (BMI), residence in Taipei/New Taipei City, body temperature at the emergency room (ER), white blood cell count (WBC), and time interval from symptom onset to ER arrival. The weighted Charlson comorbidity index (CCl) score was used to account for the comorbidity burden.[16, 17] Further, daily confirmed COVID-19 cases were recorded to represent the severity of the pandemic. The primary outcome measure was the occurrence of 
ACA defined as abscess observed in computed tomography, presence of appendiceal perforation determined by surgical documentation, or a description of gangrenous appendicitis assessed by pathological reports.[10] The secondary outcome measure was inpatient length of stay.

Statistical analyses were performed using the Statistical Package for the Social Sciences (SPSS) version 26.0 software (IBM SPSS 26.0, Armonk, NY). Continuous variables were presented as median with interquartile ranges (IQRs), and categorical variables were expressed as numbers (percentages). Categorical variables were compared using the Chi-square test or Fisher's exact test (the numbers were < 5). Continuous variables between groups were compared using the Mann-Whitney $U$ test. One binary logistic regression model was used on associated variables to determine the odds of ACA occurrence. Further, a linear regression model was created to predict the length of hospital stays. Statistical significance was assumed at $\mathrm{P}<0.05$.

\section{Results}

During the 26-week COVID-19 study period, 145 patients with AA were treated in our institute (Table 1). No patient was diagnosed with COVID-19. Among them, 43 (29.7\%) patients had ACA. The rate of appendectomy between the ACA and non-ACA groups was $83.7 \%$ and $98.0 \%$, respectively. Patients with ACA had a significantly higher rate of body temperature $\left(>38^{\circ} \mathrm{C}(46.5 \%\right.$ vs $26.5 \%, P=0.019)$ and a significantly higher rate of symptom duration until their presentation to the ER within $>48 \mathrm{~h}(20.9 \% \mathrm{vs}$ $8.8 \%, P=0.001)$ in comparison with non-ACA. No differences were observed in the median age, gender, $\mathrm{BMI}$, or $\mathrm{CCl}$ score category between adults with ACA and non-ACA. 
Table 1

Clinical variables among 145 adult patients with acute appendicitis during the COVID-19 outbreak

\begin{tabular}{|c|c|c|c|}
\hline & $\begin{array}{l}\text { Non-complicated } \\
\text { appendicitis } \\
(\mathrm{N}=102)\end{array}$ & $\begin{array}{l}\text { Complicated } \\
\text { appendicitis } \\
(\mathrm{N}=43)\end{array}$ & $\begin{array}{l}P \\
\text { value }\end{array}$ \\
\hline Age, y, median (IQR) & $55.5(36.8,65.1)$ & $53.3(36.4,65.5)$ & 0.710 \\
\hline Gender & & & 0.360 \\
\hline Female & $46(45.1 \%)$ & $23(53.5 \%)$ & \\
\hline Male & $56(54.9 \%)$ & $20(46.5 \%)$ & \\
\hline Body mass index, median (IQR) & $23.0(21.3,25.2)$ & $23.5(21.0,25.1)$ & 0.970 \\
\hline Charlson comorbidity index score & & & 0.140 \\
\hline$<=2$ & $97(95.1 \%)$ & $38(88.4 \%)$ & \\
\hline$>2$ & $5(4.9 \%)$ & $5(11.6 \%)$ & \\
\hline Residence in Taipei/New Taipei City & $93(91.2 \%)$ & $38(88.4 \%)$ & 0.690 \\
\hline $\begin{array}{l}\text { Duration of symptoms until presentation } \\
\text { to } E R, n(\%)\end{array}$ & & & 0.001 \\
\hline$<=48 \mathrm{~h}$ & $93(91.2 \%)$ & $33(79.1 \%)$ & \\
\hline$>48 \mathrm{~h}$ & $9(8.8 \%)$ & $9(20.9 \%)$ & \\
\hline $\begin{array}{l}\text { Time from ER visit to surgery (hours), } \\
\text { median (IQR) }\end{array}$ & $11.0(10.0,14.0)$ & $13.0(11.0,15.0)$ & 0.190 \\
\hline Body temperature $>38$ Celsius degrees & $27(26.5 \%)$ & $20(46.5 \%)$ & 0.019 \\
\hline White blood count, $10^{9} / \mathrm{L}$, median (IQR) & $11.0(9.0,14.8)$ & $10.2(7.9,11.7)$ & 0.170 \\
\hline Appendectomy performed & $100(98.0 \%)$ & $36(83.7 \%)$ & 0.001 \\
\hline $\begin{array}{l}\text { Length of hospital stays (day), median } \\
\text { (IQR) }\end{array}$ & $4.0(3.0,7.0)$ & $5.0(3.0,11.0)$ & 0.080 \\
\hline ER: emergency room & & & \\
\hline
\end{tabular}

To determine the impact of the COVID-19 pandemic on the severity of appendicitis, Fig. 1 shows the association between the number of confirmed COVID-19 cases in Taiwan and the distribution of patients with AA. The majority of COVID-19 cases is diagnosed from week 6 to 16. The ACA ratio during the same period was also increased.

For comparisons during the COVID-19 period, a control cohort comprising of 320 patients was identified over 18 months between 2017 and 2019 (Table 2). No differences were observed in median age, gender, 
median BMI, category of $\mathrm{CCl}$ score, and residence in Taipei/New Taipei City between the two groups. The median WBC count (10.8 vs $\left.9.4 \times 10^{9} / \mathrm{L}, P=0.010\right)$ and rate of symptom duration until their presentation to the ER within $>48 \mathrm{~h}(17.2 \%$ vs $9.1 \%, P=0.011)$ were significantly higher during the COVID-19 period as compared to the control period. Overall, a higher incidence of ACA $(29.7 \%$ vs $19.4 \%, P=0.014)$ and a longer length of hospital stays ( 5.0 days vs 4.0 days, $P=0.043$ ) were observed during the COVID-19 period.

\section{Table 2}

Comparison of clinical characteristics between adult patients with acute appendicitis during the COVID19 epidemic period and the preceding 3-year control period

\begin{tabular}{|c|c|c|c|}
\hline & $\begin{array}{l}\text { Control period } \\
(\mathrm{N}=320)\end{array}$ & $\begin{array}{l}\text { CoVID-19 } \\
\text { period } \\
(\mathrm{N}=145)\end{array}$ & $P$ value \\
\hline Age, y, median (IQR) & $\begin{array}{l}47.9(33.4 \\
63.4)\end{array}$ & $\begin{array}{l}55.2(36.8 \\
65.4)\end{array}$ & 0.088 \\
\hline Gender & & & 0.220 \\
\hline Female & $172(53.8 \%)$ & $69(47.6 \%)$ & \\
\hline Male & $148(46.3 \%)$ & $76(52.4 \%)$ & \\
\hline Body mass index, median (IQR) & $\begin{array}{l}23.0(21.0 \\
24.7)\end{array}$ & $\begin{array}{l}23.1(21.3 \\
25.1)\end{array}$ & 0.210 \\
\hline Charlson comorbidity index score & & & 0.690 \\
\hline$<=2$ & $301(94.1 \%)$ & $135(93.1 \%)$ & \\
\hline$>2$ & $19(5.9 \%)$ & $10(6.9 \%)$ & \\
\hline Residence in Taipei/New Taipei City & $290(90.6 \%)$ & $131(90.3 \%)$ & 0.920 \\
\hline $\begin{array}{l}\text { Duration of symptoms until presentation to } E R, n \\
(\%)\end{array}$ & & & 0.011 \\
\hline$<=48 \mathrm{~h}$ & $291(90.9 \%)$ & $120(82.8 \%)$ & \\
\hline$>48 \mathrm{~h}$ & $29(9.1 \%)$ & $25(17.2 \%)$ & \\
\hline Time from ER visit to surgery (hours), median (IQR) & $10.0(9.0,13.0)$ & $\begin{array}{l}11.0(10.0 \\
14.0)\end{array}$ & 0.340 \\
\hline Body temperature $>38$ Celsius degrees & $129(40.3 \%)$ & $47(32.4 \%)$ & 0.100 \\
\hline White blood count, $10^{9} / \mathrm{L}$, median (IQR) & $9.4(7.6,11.6)$ & $10.8(8.9,13.2)$ & 0.010 \\
\hline Complicated appendicitis & $62(19.4 \%)$ & $43(29.7 \%)$ & 0.014 \\
\hline Length of hospital stays (day), median (IQR) & $4.0(3.0,6.0)$ & $5.0(3.0,8.0)$ & 0.043 \\
\hline ER: emergency room & & & \\
\hline
\end{tabular}


To validate the association between COVID-19 period and ACA onset, one binary multivariate model was developed to predict the ACA occurrence (Table 3 ), showing that both COVID-19 periods (odds ratio [OR] = $1.87 ; 95 \%$ confidence interval $[\mathrm{Cl}]: 1.23-2.52 ; \mathrm{P}=0.008$ ) and symptom duration until their presentation to the ER within $>48 \mathrm{~h}(\mathrm{OR}=1.70 ; 95 \% \mathrm{Cl}: 1.06-2.36 ; \mathrm{P}=0.044)$ were significantly associated with the ACA development. Further, one adjusted linear regression model was used to predict the length of hospital stays (Table 4), demonstrating that both $\mathrm{CCl}$ scores of $>2$ (coefficient $=2.51 ; 95 \% \mathrm{Cl}$ : 1.25 to $3.16 ; P<$ 0.001 ) and COVID-19 period (coefficient $=2.10 ; 95 \% \mathrm{Cl}$ : 0.92 to $3.31 ; P<0.001$ ) were significantly associated with longer length of hospital stays.

Table 3

Adjusted multivariate analysis to predict complicated appendicitis

\begin{tabular}{|llll|}
\hline Variables & Odds ratio & $95 \%$ Cl & $P$ value \\
\hline Age (every one-year increment) & 1.01 & $0.99-1.02$ & 0.245 \\
\hline Male gender (ref: female) & 0.93 & $0.58-1.50$ & 0.793 \\
\hline Body mass index & 0.93 & $0.86-1.01$ & 0.132 \\
\hline Charlson comorbidity index score $>$ 2 (ref: <=2) & 1.38 & $0.58-3.28$ & 0.459 \\
\hline Residence in Taipei/New Taipei City & 0.76 & $0.40-1.42$ & 0.395 \\
\hline Duration of symptoms until presentation $>$ 48 h (ref: $<=48$ h) & 1.70 & $1.06-2.36$ & 0.044 \\
\hline Body temperature > 38 celsius degrees & 0.74 & $0.35-1.57$ & 0.446 \\
\hline White blood counts & 1.01 & $0.76-2.97$ & 0.985 \\
\hline COVID-19 period (ref: control period: 2017-2019) & 1.87 & $1.23-2.52$ & 0.008 \\
\hline
\end{tabular}

Table 4

Adjusted multivariate analysis to predict inpatient length of stay

\begin{tabular}{|c|c|c|c|c|}
\hline \multirow[t]{2}{*}{ Variables } & \multirow[t]{2}{*}{ Coefficients } & \multicolumn{2}{|c|}{$95 \%$ confident interval } & \multirow[t]{2}{*}{$P$ value } \\
\hline & & Lower limit & Upper limit & \\
\hline Age (every one-year increment) & 0.16 & -0.02 & 0.13 & 0.524 \\
\hline Male gender (ref: female) & 0.64 & -1.93 & 3.21 & 0.627 \\
\hline Body mass index & -0.15 & -0.60 & 0.31 & 0.530 \\
\hline Charlson comorbidity index score > 2 (ref: $<=2)$ & 2.51 & 1.25 & 3.16 & $<0.001$ \\
\hline Residence in Taipei/New Taipei City & -3.05 & -7.4 & 1.29 & 0.168 \\
\hline Complicated appendicitis & 2.1 & 0.92 & 3.31 & $<0.001$ \\
\hline
\end{tabular}

\section{Discussion}


The COVID-19 pandemic was the most concerning health problem in 2020 because it caused not only healthy disorders but also extensive restrictions of daily life worldwide. During our study period, Taiwan was exempted from the pandemic due to the implementation of broad public health infrastructure and domains of effective screening, isolation/quarantine, and facial mask use.[18] Although Taiwan's government did not implement travel restrictions and the medical supply was competent, this study demonstrated a higher rate of ACA and a longer length of hospital stays in patients with AA during the COVID-19 study period. Notably, the number of confirmed COVID-19 was positively correlated with the ACA rate. Therefore, the patients' fear of being contaminated by the COVID-19 influenced the HSB and deteriorated the clinical outcomes.

In our study, the symptom duration from the ER presentation to $>48 \mathrm{~h}$ thereafter was significantly associated with ACA, which was similar to that of a previous report.[19] Prolonged appendicitis without prompt treatment might deteriorate the inflammation of the appendiceal wall and result in perforation or abscess formation.[20] Furthermore, one significant association was observed between patients with AA during the COVID-19 period and ACA as compared with that in the last 33 years. Our finding coincided with that of published reports in children [12, 21] and adults.[22]

In addition to the impact of clinical and socioeconomic determinants on outcomes, poor HSB has been proven to increase morbidity and mortality.[23] Patients' behaviors should be understood at their level to improve their clinical outcomes.[24] Based on our findings, one epidemic communicable disease could interfere with the need of seeking medical services even in a resource-competent community. We consider that some fake news or information in social media causes fear of the people, who diminish the travel and need of seeking medical services.[25] Conversely, scientific information and medical knowledge can help improve the HSB, which in turn enhances the healthy condition.[23] Although social media can rapidly disseminate any information, some false information can confuse and distract people. Therefore, reliable evidence is the cornerstone of promoting health awareness and implementing health policy, especially during the COVID-19 pandemic. Moreover, educated scientists and physicians will be leaders in delivering information to the public, $[25,26]$ and the government should implement anti-misinformation actions to minimize the adverse effects.

Although healthcare system, disparities of medical supplies, and socioeconomic status are the main barriers to medical services,[27, 28] an extensive health crisis during the COVID-19 pandemic may become the additional obstacle to providing timely surgical intervention, a basis of any healthcare system with both elective and emergency procedures. To overcome the shortage of medical services, healthcare systems should rapidly prioritize available resources and adopt new policies to deliver clinical services.[29, 30] Although surgical management widely varies in terms of regional culture and healthcare system worldwide, each institution customizes associated plans to maintain appropriate surgical services when surgical staff are sufficiently protected.

This study had some limitations. The study design was retrospective and was conducted in one universal healthcare system, which alleviates part of the barrier of access to healthcare services. Second, from 
January 1 to June 30,2020 , was selected because the dissemination of COVID-19 is severer during this period. Different periods might interfere with the results. Third, the referral policy was associated with delayed medical visits but was consistent during the study period in Taiwan. Some studies addressed that general practitioners preferred medical treatment for patients with AA without referring them to the ER.[31] From our findings, the number of patients with AA (145) was higher than the average number during the control period (around 107). Therefore, we considered that the number of patients who were not referred for or received no medical treatment was rather low.

\section{Conclusions}

The COVID-19 pandemic was significantly associated with a delayed presentation to the ER and increased ACA rate even though one community had normal medical supply and had no travel restriction. Educated scientists and physicians should play a key role in not only delivering information and knowledge to relieve the fear of people but also encouraging patients to seek prompt medical services. These implications may alleviate the collateral impact of this communicable disease on other surgical diseases. In addition, the COVID-19 outbreak will further deteriorate the medical supply, and healthcare systems should adopt new policies and allocate resources to maintain surgical services with the coverage of workplace safety.

\section{Abbreviations}

HSB

Health-seeking behavior; SARS-CoV-2:severe acute respiratory syndrome coronavirus disease 2; COVID19:coronavirus disease 2019; AA:Acute appendicitis; ACA:acute complicated appendicitis; CCI:Charlson comorbidity index; BMI:body mass index; ER:emergency room; WBC:white blood cell count; SPSS:Statistical Package for the Social Sciences.

\section{Declarations}

\section{Ethics approval and consent to participate}

This study was reviewed and approved by the research ethics committee of the National Taiwan University Hospital (202008052RINC). The requirement for obtaining informed consent from patients was waived because the data sets were anonymous.

\section{Consent for publication}

Not applicable.

\section{Availability of data and materials}


The datasets generated during and/or analysed during the current study are available from the corresponding author on reasonable request.

\section{Competing interests}

All authors have no conflicts of interest or financial ties to disclose.

\section{Funding}

This study was supported by grant from NTUH (109-P22) and grants from the Ministry of Science and Technology (Numbers 110-2634-F-002 -032 and 110-2811-E-002 -528 -MY3), Taiwan, which had no role in study design, data collection and analysis, decision to publish, or preparation of the manuscript.

\section{Authors' contributions}

Conceptualization, Data curation, Investigation, Project administration, Resources, Writing - original draft: J-M W, T-W H, H-Y Y, and I-R L.

\section{References}

1. Chrisman NJ. The health seeking process: an approach to the natural history of illness. Cult Med Psychiatry. 1977;1:351-77.

2. Andersen RM. Revisiting the behavioral model and access to medical care: does it matter? J Health Soc Behav. 1995;36:1-10.

3. Clewley D, Rhon D, Flynn T, et al. Health seeking behavior as a predictor of healthcare utilization in a population of patients with spinal pain. PLoS One. 2018;13:e0201348.

4. Andersen RM. National health surveys and the behavioral model of health services use. Med Care. 2008;46:647-53.

5. Blackwell DL, Martinez ME, Gentleman JF, et al. Socioeconomic status and utilization of health care services in Canada and the United States: findings from a binational health survey. Med Care. 2009;47:1136-46.

6. Zhu N, Zhang D, Wang W, et al. A Novel Coronavirus from Patients with Pneumonia in China, 2019. N Engl J Med. 2020;382:727-33.

7. https://.

8. Boserup B, McKenney M, Elkbuli A. The impact of the COVID-19 pandemic on emergency department visits and patient safety in the United States. Am J Emerg Med. 2020;38:1732-6.

9. Addiss DG, Shaffer N, Fowler BS, et al. The epidemiology of appendicitis and appendectomy in the United States. Am J Epidemiol. 1990;132:910-25. 
10. Bhangu A, Soreide K, Di Saverio S, et al. Acute appendicitis: modern understanding of pathogenesis, diagnosis, and management. Lancet. 2015;386:1278-87.

11. Sartelli M, Baiocchi GL, Di Saverio S, et al. Prospective Observational Study on acute Appendicitis Worldwide (POSAW). World journal of emergency surgery: WJES. 2018;13:19.

12. Fisher JC, Tomita SS, Ginsburg HB, et al. Increase in Pediatric Perforated Appendicitis in the New York City Metropolitan Region at the Epicenter of the COVID-19 Outbreak. Ann Surg. 2021;273:410-5.

13. Burgard M, Cherbanyk F, Nassiopoulos K, et al. An effect of the COVID-19 pandemic: Significantly more complicated appendicitis due to delayed presentation of patients! PLoS One. 2021;16:e0249171.

14. Wang CJ, Ng CY, Brook RH. Response to COVID-19 in Taiwan: Big Data Analytics, New Technology, and Proactive Testing. JAMA. 2020;323:1341-2.

15. Zangbar B, Rhee P, Pandit V, et al. Seasonal Variation in Emergency General Surgery. Ann Surg. 2016;263:76-81.

16. Quan H, Li B, Couris CM, et al. Updating and validating the Charlson comorbidity index and score for risk adjustment in hospital discharge abstracts using data from 6 countries. Am J Epidemiol. 2011;173:676-82.

17. Wu JM, Ho TW, Yen HH, et al. Endoscopic Retrograde Biliary Drainage Causes Intra-Abdominal Abscess in Pancreaticoduodenectomy Patients: An Important But Neglected Risk Factor. Ann Surg Oncol. 2019;26:1086-92.

18. Summers J, Cheng HY, Lin HH, et al. Potential lessons from the Taiwan and New Zealand health responses to the COVID-19 pandemic. Lancet Reg Health West Pac. 2020;4:100044.

19. Tsioplis C, Brockschmidt C, Sander S, et al. Factors influencing the course of acute appendicitis in adults and children. Langenbecks Arch Surg. 2013;398:857-67.

20. Perez KS, Allen SR. Complicated appendicitis and considerations for interval appendectomy. JAAPA. 2018;31:35-41.

21. Schafer FM, Meyer J, Kellnar S, et al. Increased Incidence of Perforated Appendicitis in Children During COVID-19 Pandemic in a Bavarian Multi-Center Study. Front Pediatr. 2021;9:683607.

22. Orthopoulos G, Santone E, Izzo F, et al. Increasing incidence of complicated appendicitis during COVID-19 pandemic. American journal of surgery. 2021;221:1056-60.

23. Saah FI, Amu H, Seidu AA, et al. Health knowledge and care seeking behaviour in resource-limited settings amidst the COVID-19 pandemic: A qualitative study in Ghana. PLoS One. 2021;16:e0250940.

24. Boslaugh S. Encyclopedia of epidemiology. Sage Publications; 2007.

25. Venegas-Vera AV, Colbert GB, Lerma EV. Positive and negative impact of social media in the COVID19 era. Rev Cardiovasc Med. 2020;21:561-4.

26. Mheidly N, Fares J. Leveraging media and health communication strategies to overcome the COVID19 infodemic. J Public Health Policy. 2020;41:410-20. 
27. Kishore SP, Kolappa K, Jarvis JD, et al. Overcoming Obstacles To Enable Access To Medicines For Noncommunicable Diseases In Poor Countries. Health Aff (Millwood). 2015;34:1569-77.

28. Wu JM, Ho TW, Tien YW. Correlation Between the Increased Hospital Volume and Decreased Overall Perioperative Mortality in One Universal Health Care System. World J Surg. 2019;43:2194-202.

29. Berlin NL, Dimick JB, Kerr EA, et al. Demand for Surgical Procedures Following COVID-19: The Need for Operational Strategies That Optimize Resource Utilization and Value. Ann Surg. 2020;272:e2724.

30. Al-Jabir A, Kerwan A, Nicola M, et al. Impact of the Coronavirus (COVID-19) pandemic on surgical practice - Part 1. Int J Surg. 2020;79:168-79.

31. Tankel J, Keinan A, Blich O, et al. The Decreasing Incidence of Acute Appendicitis During COVID-19: A Retrospective Multi-centre Study. World J Surg. 2020;44:2458-63.

\section{Figures}

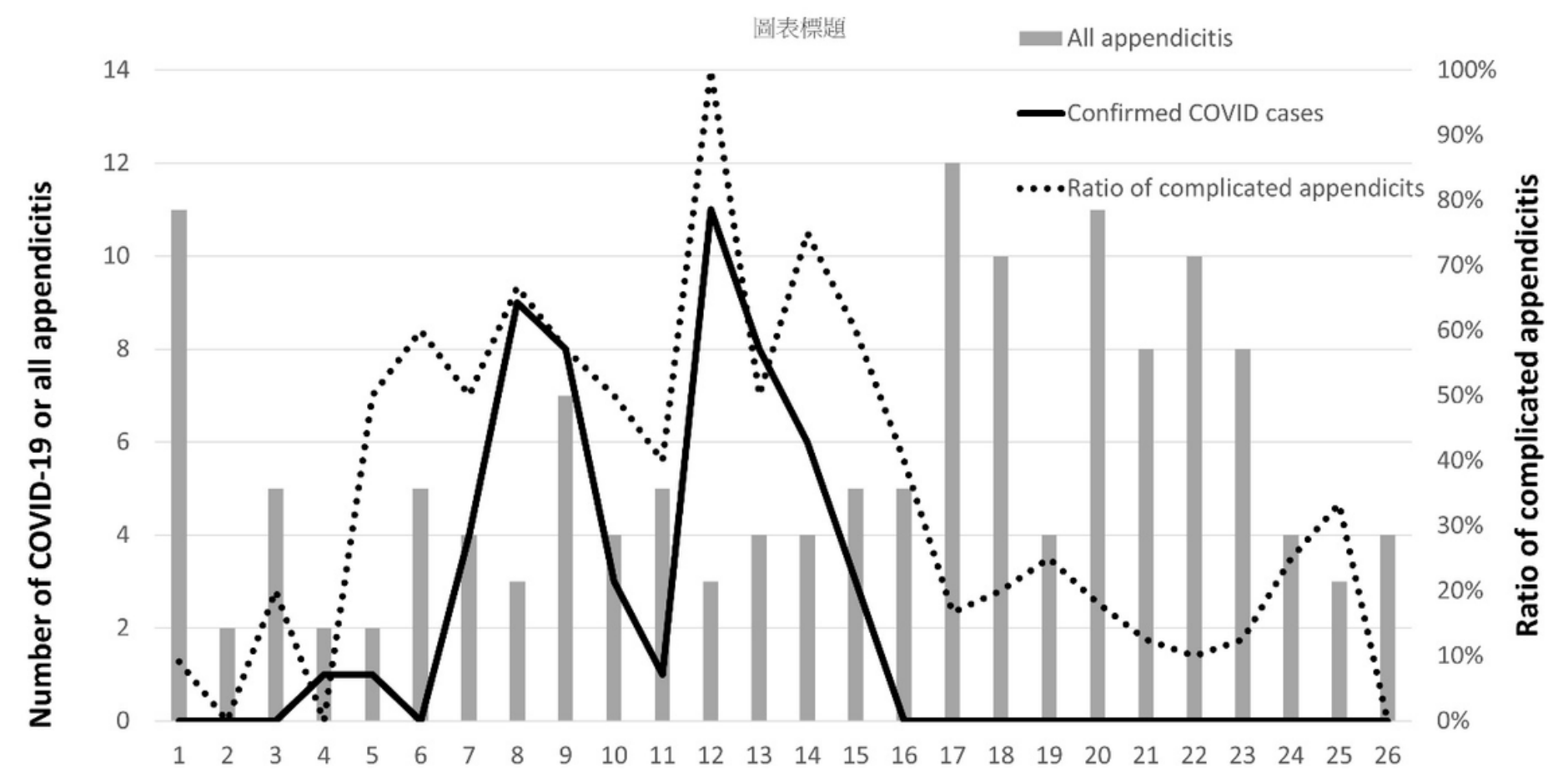

Time period by week (01/01/2020 - 30/06/2020)

\section{Figure 1}

Weekly statistics on the number of adult patients with acute appendicitis (dotted vertical bar), the number of complicated appendicitis (solid vertical bar), and confirmed COVID-19 cases in Taiwan (dashed line). 